\title{
66 ALGORITHM FOR CONSTRAINING EARTHQUAKE SOURCE DOMAINS AND ESTIMATING THEIR POTENTIAL MAGNITUDES FROM GEOPHYSICAL DATA,
}

\author{
Viacheslav V. Spichak ${ }^{1}$ \\ (1) Institute of Physics of the Earth RAS, Moscow, Russia
}

Article history

Receveid January 30, 2018; accepted November 22, 2018.

Subject classification:

Seismicity; Earthquake source; Magnitude forecast; Geophysical models; Elastic moduli; Neural network.

\begin{abstract}
A two-stage algorithm for constraining earthquake source domains and estimating expected magnitudes of the potential earthquakes is suggested. Constraining of the EQ source domains in the crystalline crust of the study area is carried out by means of geophysical proxies derived from comparison of physical and mechanical properties of rocks in the hypocenters of past earthquakes and in the nodes of 3D grid covering appropriate models. At the second stage forecasting of the expected EQ magnitudes in the constrained source domains is fulfilled using artificial neural network taught by correspondence of the shear modulus determined in the hypocenters of past earthquakes and EQ magnitudes. Application of this algorithm to the Altai-Sayan seismically active area enabled to delineate earthquake source domains at different depths. Two of them were previously guessed from the surface seismicity data and interpreted in terms of the fault tectonics, whereas others have been constrained for the first time. The results of research indirectly support the hypothesis that rheological weakness of rocks is likely to be responsible for common physical and mechanical conditions controlling the occurrence of the earthquakes and evolution of the faults. Another important inference is that neither the statistical information on past seismicity alone nor speculations on fault tectonics are sufficient to constrain the ESDs in the Earth's crust.
\end{abstract}

\section{INTRODUCTION}

Simultaneous forecasting of the earthquake's (EQ) spatial location, timing and magnitude is unrealistic task. If timing is removed from the target parameters the problem is usually reduced to constraining of "earthquake prone zones" at the surface. Their location and appropriate dimensions are traditionally estimated using probabilistic seismic hazard analysis (PSHA) by methods of statistical physics [see, for instance, Kossobokov et al., 2000] or pattern recognition techniques [Gelfand et al., 1972; Caputo et al., 1980; Gorshkov et al., 2003, 2009; Zaalishvili and Rogojin, 2011; Gvishiani et al., 2018; Scitovski, 2018; among others] resulting in seismic zonation maps for different regions
[Frankel et al., 1996; Maps of regional seismic zoning..., 1999; Khair et al., 2000; Gao, 2003; Petrini and Boni, 2004; Solomos et al., 2008; Mohapatra and Mohanty, 2010; Putra et al., 2012; Leonard et al., 2013; Wenk, 2014; Artikov et al., 2016; Vamvakaris et al., 2016; among others].

However, seismic zoning of the territory based on the probabilistic seismic hazard analysis does not always result in useful hazard maps (see the main drawbacks of this approach indicated by Stein et al., 2012 and Mulargia et al., 2017; 2018). Unfortunately, the seismicity data together with the relationship between the earthquake intensity and occurrence frequency can only predict the average recurrence interval of the earthquakes of a given energy class in the considered 
region and tell nothing about possible magnitudes of the events. For instance, during a few past years, the territory of the former USSR was hit by four earthquakes whose intensity at the epicenter was 8 to 10 and the sources were located in the areas where the maximal magnitude of the earthquakes was estimated at 7 and even 5 [Earthquakes in the USSR, 1991; Earthquakes in the Northern Eurasia, 2005]. This is particularly important when we assess the seismic hazards in the territories with weak seismic activity, for which the statistical data are typically scarce and accurate information about more or less significant earthquakes is often completely absent.

Alternative approach consists in mapping and justification of probable EQ sources from seismotectonic reconstructions [Lomnitz, 1974; Eppelbaum and Katz, 2016; among others], which implicitly supposes that seismic sources are associated with certain geological structures, e.g., large faults. For instance, most of wellstudied earthquakes in USA are confined to the San Andreas fault zone where the largest seismic ruptures have a strike-slip mechanism and a linear shape not complicated by secondary fault branches [The San Andreas..., 1990]. On the other hand, there is an evidence that some earthquakes in Western California [Jonson and Fleming, 1993; Wald et al., 1994], New Madrid seis- mogenic zone [New Madrid seismic zone..., 2003; Harrison and Schultz, 1994], West Macedonia [Chadzipetros et al., 1998], etc., have volumetric sources which are not directly related to seismotectonics.

Similarly, there is some seismicity in the areas of spatial convergence of some faults in the south-eastern Altai-Syan (Russia). However, the other faults of this seismically active territory do not seismically display themselves. Moreover, in a number of highly active regions of this territory (East Tuva uplands, Mongolian Altai), such faults have not been identified at all [Zhalkovskii et al., 1995]. Therefore, despite of earthquakes are triggered by tectonic or volcanic activity as well as by landslides, nuclear blasts, etc. it is probably more reasonable to suppose presence of common conditions controlling occurrence of earthquakes and development of faults rather than direct linkage between the sources of the incipient earthquakes and preexisting fault dislocations.

Moreover, the background seismicity pattern is often quasi-stationary (see, for instance, [Wyss and Toya, 2000; Emanov et al., 2005]). This could be explained supposing that it is constrained by specific physical and mechanical rock properties, which are associated with the structure of their crystal lattices not varying with time. Krylov and Ten [1995] studied strength and elas-

GEOPHYSICAL DATA

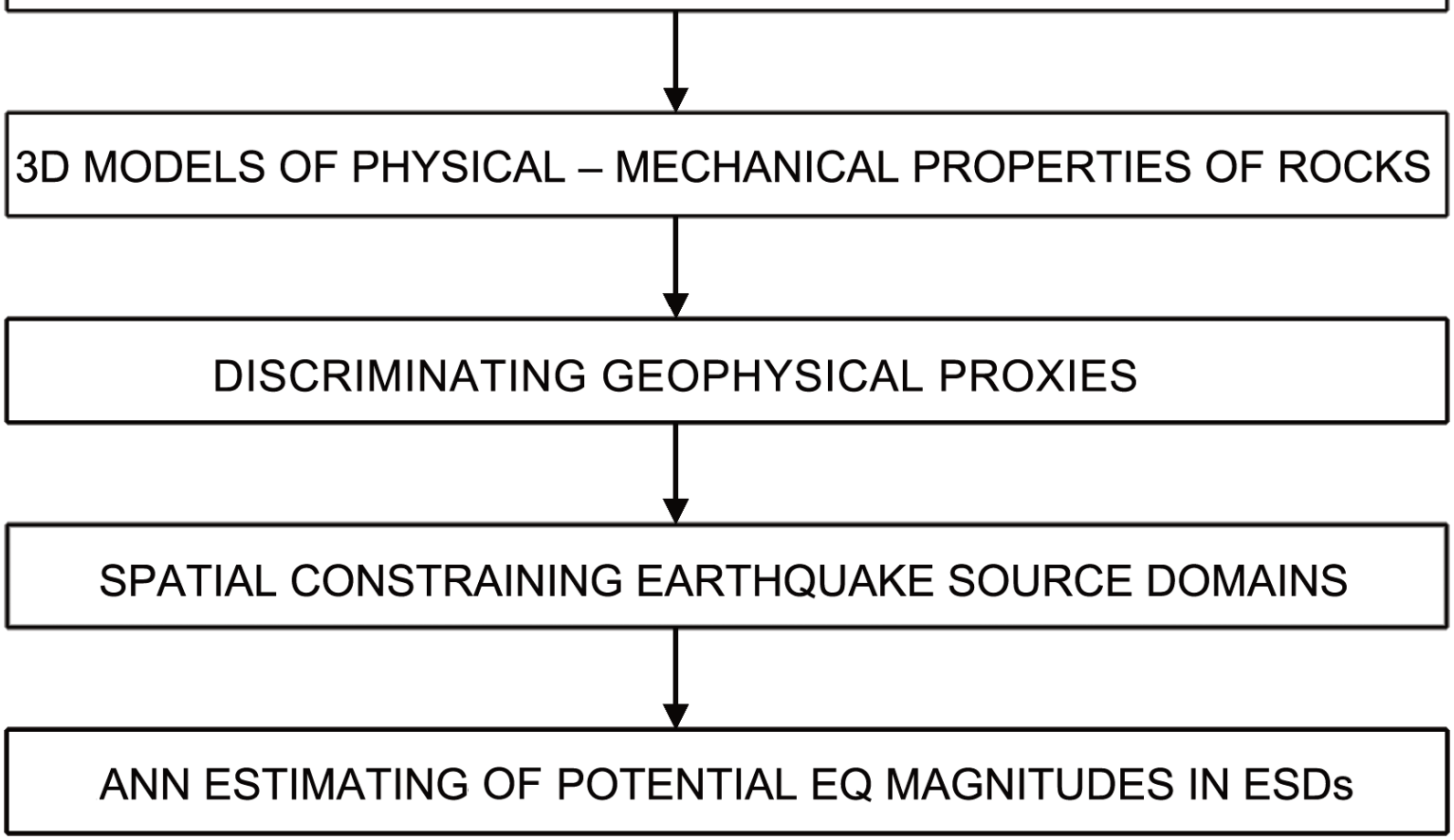

FIGURE 1. Structural chart of the methodology of the EQ magnitudes' estimating in the EPDs. 
tic properties of rocks in the source zones of violent earthquakes within the Baikal and northern Tien Shan areas, while Krylov and Duchkov [1996] estimated correlation between the hypocenters' locations and anomalies of seismic velocities and elastic moduli. However, since this approach only relied on the laboratory measurements and due to the lack of the required geophysical data, its efficiency remained uncertain.

Spichak [2016] has suggested a new approach to constraining earthquake source domains (ESD) in the crystalline crust from geophysical data. In the first part of the paper an appropriate formalized algorithm is formulated and applied to the seismically active AltaiSayan area. In the second part of the paper an artificial neural network (ANN) based methodology for EQ magnitudes' estimating in the ESDs is suggested. Figure 1 illustrates a structural chart of the work. After geological setting and seismicity description (Sections 1 and 2, accordingly) 3-D geophysical models built for this area earlier [Spichak et al., 2015] are considered (Section 3). Algorithm for constraining ESDs in the crust based on selection of geophysical proxies is discussed in the Section 4. Finally, in the Section 5 expected magnitudes of possible earthquake in the revealed ESDs are estimated.

\section{TECTONICS AND SEISMICITY OF THE REGION}

\subsection{TECTONICS}

The study area is located in Tuva region of Altai-Sayan (Russia) (Figure 2a). The tectonics of this area is controlled mainly by overlapping of uplifted Tuva mountain massifs oriented along the latitude and the Mountainous Altai structures striking northwest. The combination of elevated rock masses and Tuva depression (indicated in the Figure $2 \mathrm{~b}$ by green color) makes up a cellular structure. According to [Zhalkovskii et al., 1995], the characteristics of the crustal stress state suggest that the considered area is composed of two zones with slightly different orientation of the principal stress axes in the Earth's crust. The conditional boundary between these zones runs along the Shapshal Ridge (see its location in Figure 2b). The crust is dominated by the quasi-horizontal compression in the NNW and NNE directions within the western and eastern parts, respectively.

Seismicity of the study area was analyzed by Emanov et al. [2005] along with its relief and active faults (see the relief topography and location of main faults in the Fig- ure $2 b)$. It was found that general seismicity pattern which might appear at first glance to be chaotic is stable with time and concentrating mainly in the destroyed mountain settings surrounding the Tuva depression (Figure $2 \mathrm{~b}$ ). It is more large and firm than blocks of fractured mountain ridges and sets up resistance to compression caused by slow displacement of mountain massifs from Tien Shan to Baikal through Altai, which is manifested by enhanced seismicity.

Seismicity patterns on the surface suggest that there are two seismically active areas in the western and southeastern parts of this territory - so called "Teelin" and "Shapshal source zones", respectively [Kadurin et al., 2008], determined based on total seismic energy released, geomorphology and fault tectonics. (It is worth noting in this connection that "source zones" are often considered in the scientific literature as domains in the Earth's interior located immediately beneath the surface segments characterized by the maximal seismic activity. Meanwhile, the actual location and spatial configuration of these domains often remains uncertain.)

The eastern margin of the "Teelin source zone" lies at the contact of the latitudinal Tuva depression, which is subsiding with a rate of up to $0.7 \mathrm{~mm} / \mathrm{yr}$, and the northwesterly striking West Sayan structures (not shown in Figure $2 b$ ) located to the west from Tuva depression, which are uplifting by $1.2 \mathrm{~mm} / \mathrm{yr}$. It is also confined to the frontal junction of the near-latitudinal Tuva folded area and Shapshal fault. Hence, it is possible to explain the seismic activity of the "Teelin source zone" by its position at the contact of two contrasting blocks having opposite sense of the motion (the Tuva depression and West Sayan uplifted blocks).

According to [Kadurin et al., 2008] the "Shapshal source zone" located in the southeast of the studied region is supposedly formed of the fault dislocations oriented in two directions. The first dislocation system, the Shapshal fault zone, supposedly controls the fault-block structure of the source and the configuration of the epicentral field. The Shapshal fault cuts out narrow nearmeridional band-like blocks with a width of up to $15 \mathrm{~km}$. The displacement amplitudes along them measure 200$300 \mathrm{~m}$, and the rate of uplifting is $0.6-0.7 \mathrm{~mm} / \mathrm{yr}$. The second system of the fault dislocations is oriented in the west-northwestern direction. The erosional cut has an amplitude of 2200-2500m, and the ascending motions occur at a rate of $1.2-1.4 \mathrm{~mm} / \mathrm{yr}$. The northern termination of the epicentral field falls in the southern segment of the band-like uplifted block elongated west-northwest, 


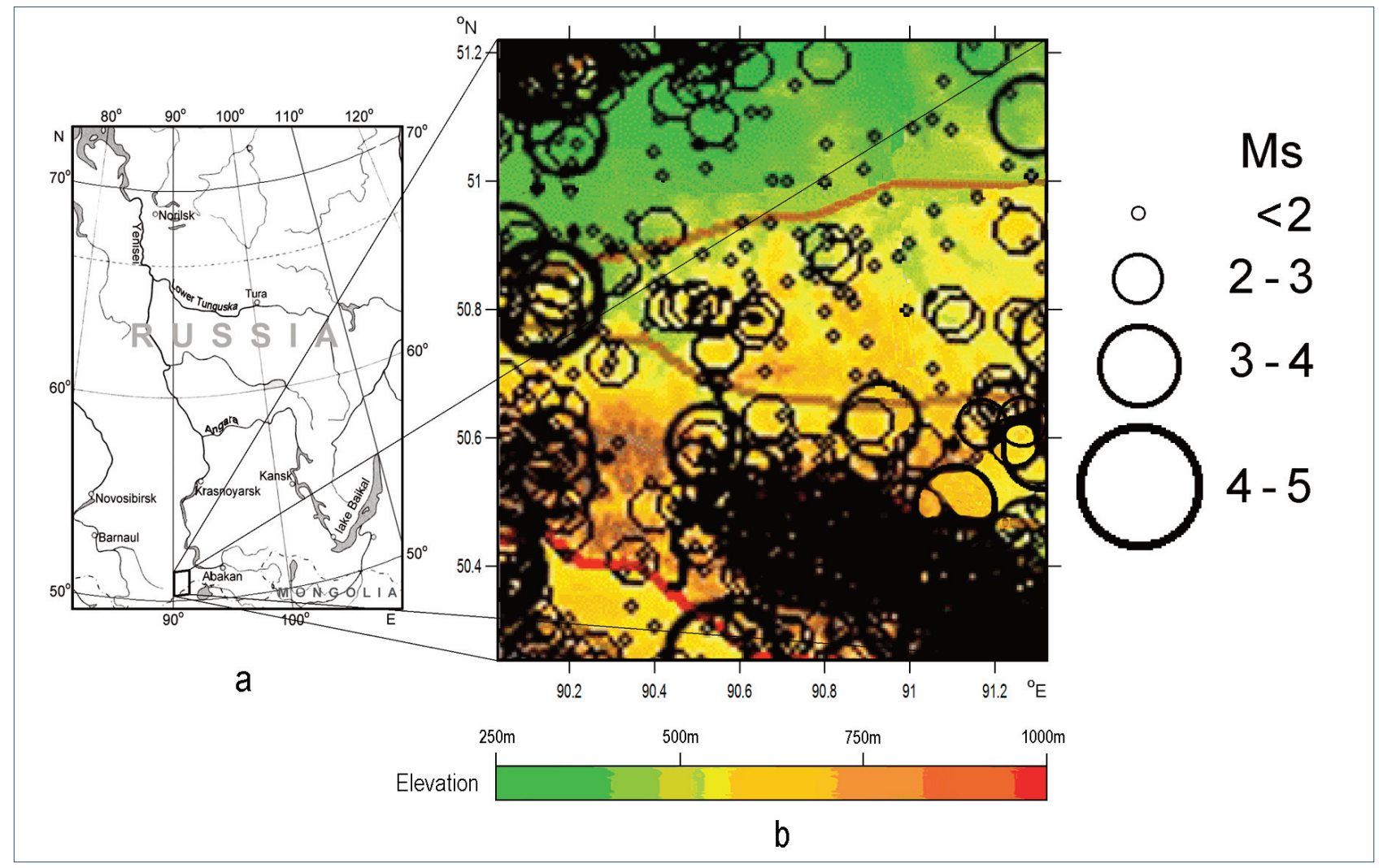

FIGURE 2. a: location of the study area; b: relief topography of the study area overlapped by circles indicating magnitudes Ms of all past earthquakes (modified after [Emanov et al., 2005]). Lines indicate faults (Shapshal is marked by red color); Tuva depression is in green color.

which forms a frontal border of the Tuva folded zone in the west.

\subsection{SEISMICITY}

The seismic events in the study area were observed since 1761. Stationary network of seismic stations was established in this area in 1962. However, due to lack of stations, their irregular distribution in the area and often insufficient accuracy of hypocenters' location (especially, of their depths) it was difficult to provide a comprehensive quantitative analysis of the seismicity pattern and its origin [Blagovidova et al., 1986]. (Probably, lack of the accurate hypocenters' depth recording is one of the common reasons for using statistical analysis of only their horizontal coordinates.) Meanwhile, these data were used (among others) for regional seismic zoning of the former USSR territory in the scale 1: 8000000 [Maps of regional seismic zoning..., 1999].

All seismicity data available presently for Altai-Sayan region are tabulated in five catalogs:

- "Earthquakes in the USSR (1962-1991)" (1991) ${ }^{1}$;

- "Earthquakes in Northern Eurasia (1992-2005)" (2005) ${ }^{2}$;
- International Seismological Centre Bulletin data base (catalog of events since 2005) ${ }^{3}$;

- Catalog of events recorded at the Tuva geodynamical site (2006-2008) ${ }^{4}$;

- Catalog of the nearby earthquakes recorded in 20062008 along the reference geotraverses cutting the study area [Kadurin et al., 2008] ${ }^{5}$.

The analysis of the cited catalogs ${ }^{1-3}$ shows that many of records do not have depth estimates, while accuracy of many others $( \pm 5-10 \mathrm{~km})$ is not appropriate for forecasting. So, in total, only 107 seismic events were selected (mainly from catalogs ${ }^{4-5}$ ) for which the hypocenters' coordinates (both horizontal and vertical) were estimated with high accuracy $( \pm 1 \div 2 \mathrm{~km})$. Fortunately, their spatial distribution (Figure 3) covers whole study area in latitude (50.26-51.22 ), longitude (90.04-91.32 $)$ and depth (4 $40 \mathrm{~km})$. The magnitudes range from 1.3 to 4.3 , which bounds only slightly narrower interval than that for the whole seismicity data pool available for this area (compare with palette in the Figure 2b). Both geographical representativeness and sufficient accuracy of the hypocenters' locations allowed using them for further quantitative estimates. 


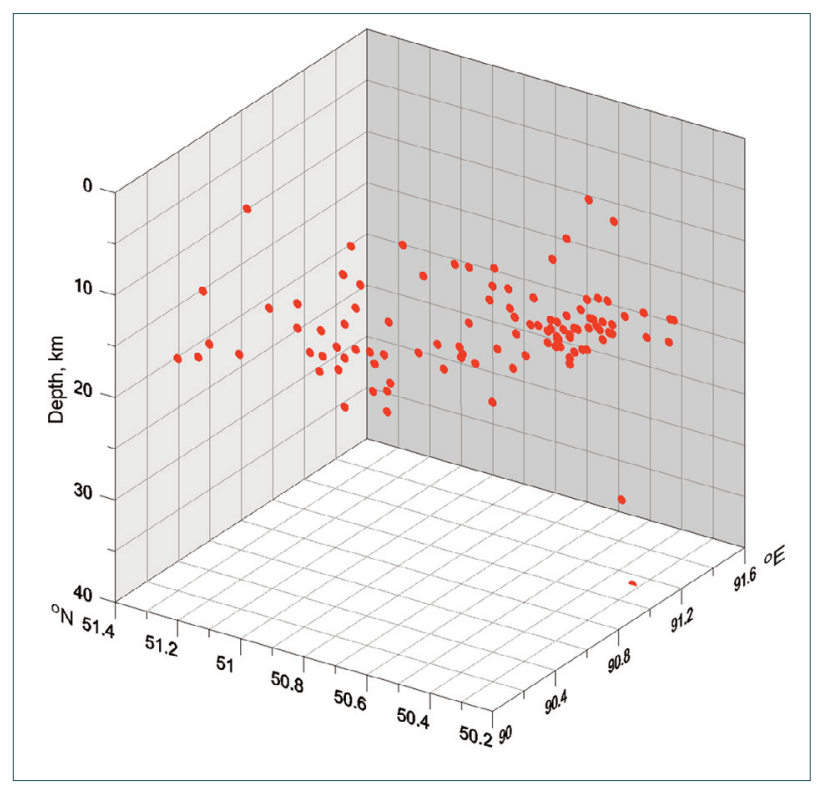

FIGURE 3. Spatial distribution of the earthquakes' hypocenters used for ANN training.

\section{THREE-DIMENSIONAL MODELS OF THE ROCKS' PHYSICAL PROPERTIES}

3-D models of the rocks' physical properties for the study area were built using the magnetotelluric (MT) sounding data [Spichak et al., 2015] and converted waves from the earthquakes recorded along a series of profiles [Kadurin et al., 2008]. The 3-D resistivity model was determined in the nodes of the uniform grid with spacing $1 \mathrm{~km}$ with an accuracy of $8 \div 10 \%$ while 3-D seismic velocities' models were determined in the nodes of a uniform grid with spacing $1 \mathrm{~km}$ in depth and $2 \mathrm{~km}$ in horizontal direction, which corresponds to the declared resolution at depth (around 1-1.5 km) and horizontal site spacing $(2 \mathrm{~km})$. The accuracy of the reconstruction of the seismic velocities is estimated as $0.1 \mathrm{~km} / \mathrm{s}$ for both compressional and shear waves. Below the key features of the built models are discussed following [Spichak et al., 2015].

The analysis of the 3-D resistivity $(\mathrm{R})$ model (Figure 4a) shows that the background crustal resistivity in the study region is at most 1000 S.m. Against this background level there are highly resistive $(\mathrm{R}>10000 \Omega . \mathrm{m})$ and conductive $(\mathrm{R} \sim 10 \Omega . \mathrm{m})$ segments. The overall resistivity distribution is mosaic: the blocks with low resistivity alternate with the highly resistive ones, reflecting the interaction between the structural-tectonic Tuva zones elongated in latitude and the northwesterly striking Altai structures. The earthquake hypocenters are concentrated within the highly resistive domains (with a resistivity of dozens of thousands of $\Omega$.m) and at the boundaries between the blocks with high and low resistivity.

The density model (Figure $4 \mathrm{~b}$ ) determined in the same grid nodes indicates that in the southwestern and northeastern segments of the studied territory there are less dense domains above a depth of $20 \mathrm{~km}$, where the density is $2.4 \div 2.7 \mathrm{~g} / \mathrm{cm}^{3}$. Thirdly, a low-density zone is revealed in the northwestern part of the region at a depth below $20 \mathrm{~km}$.

$\mathrm{Vp}$ velocities (Figure 4c) are generally lower in the western part of the region. In particular, low $\mathrm{Vp}$ are observed at a depth of $10 \div 30 \mathrm{~km}$ in the northwestern segment and at a depth of $40 \div 50 \mathrm{~km}$ in the southwestern part of the territory, where a waveguide presumably exists immediately above the Moho boundary [Kadurin et al., 2008]. The both low-velocity domains are most likely to be due to the dilatancy related fracturing of the rocks.

The velocities of the S-waves (Figure 4d) are higher in the northeastern and southwestern segments of the Earth's crust neighboring to the Shapshal fault. On the other hand, the large central diagonal band striking northwest is characterized by low Vs (up to a depth of $30 \mathrm{~km})$. In the southeast of this band, there is a zone of higher attenuation of Vs oriented along the uplifting structures of the Mountainous Altai.

The values of elastic moduli of rocks (bulk (K), shear $(\mathrm{G})$, Young $(\mathrm{Y})$ ) and Poisson ratio $(\mathrm{P})$ were determined in the same nodes of the spatial grid from the velocity and density models according to the well known formulas:

$$
\begin{gathered}
\mathrm{K}=\mathrm{D}\left(\mathrm{V}_{\mathrm{p}}{ }^{2}-4 / 3 . \mathrm{V}_{\mathrm{s}}^{2}\right) \\
\mathrm{G}=\mathrm{D} \mathrm{V_{ \textrm {s } }}{ }^{2}, \\
\mathrm{Y}=\mathrm{D} \mathrm{V_{ \textrm {s } }}\left(3 \mathrm{~V}_{\mathrm{p}}{ }^{2}-4 \mathrm{~V}_{\mathrm{s}}{ }^{2}\right) /\left[2\left(\mathrm{~V}_{\mathrm{p}}{ }^{2}-\mathrm{V}_{\mathrm{s}}{ }^{2}\right)\right], \\
\mathrm{P}=\mathrm{D}\left(\mathrm{V}_{\mathrm{p}}{ }^{2}-2 \mathrm{~V}_{\mathrm{s}}{ }^{2}\right) /\left[2\left(\mathrm{~V}_{\mathrm{s}}{ }^{2}-\mathrm{V}_{\mathrm{s}}{ }^{2}\right)\right],
\end{gathered}
$$

where $\mathrm{D}$ is the density.

\section{SPATIAL MAPPING OF THE EARTHQUAKE SOURCE DOMAINS IN THE CRUST}

As known, rocks before the earthquake are in a stressed state, and the earthquake releases these stresses. However, this concerns the external stresses but not inherent rock properties, which are associated with the structure of their crystal lattices not varying with time. 


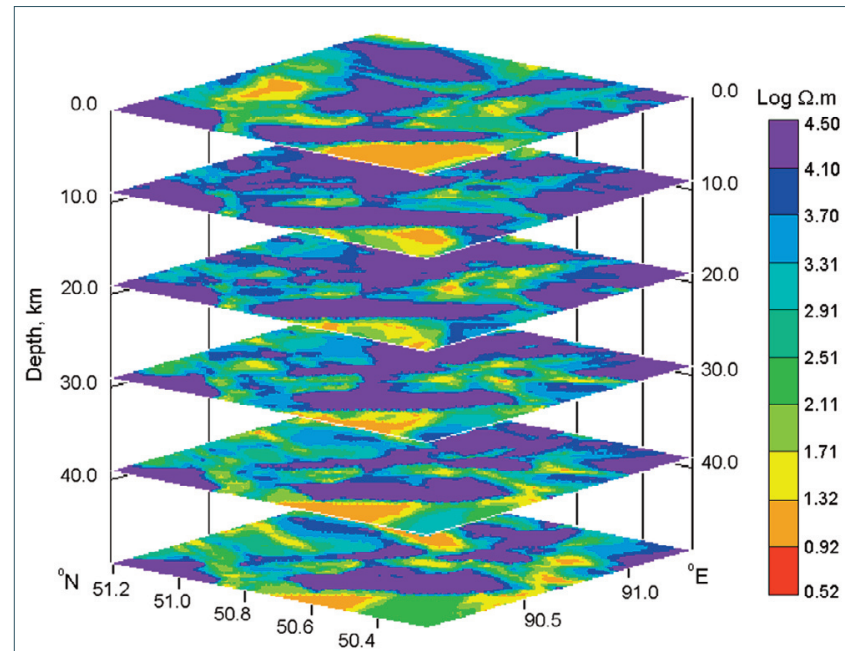

a
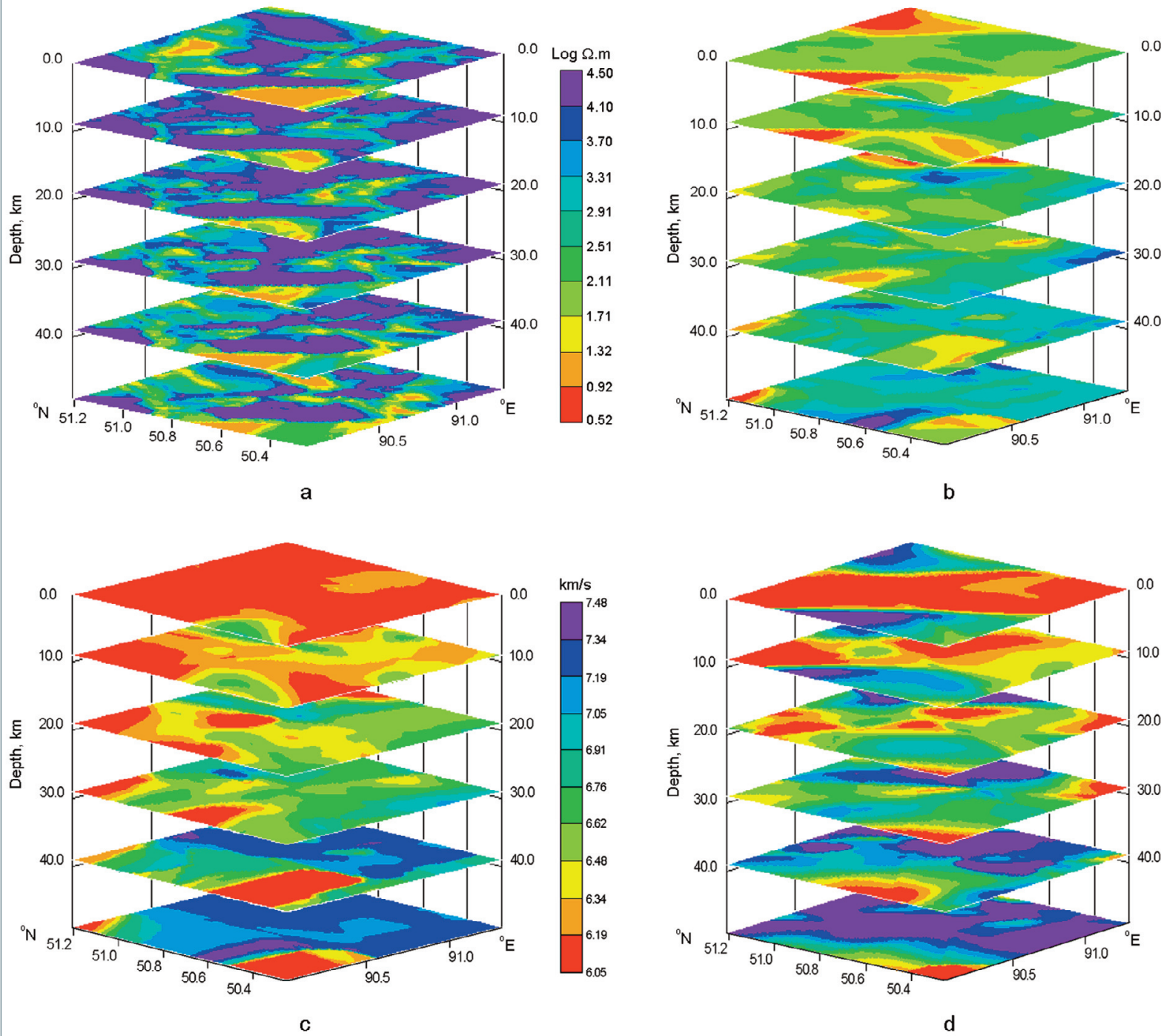

$0.0 \mathrm{~g} / \mathrm{cm}^{3}$

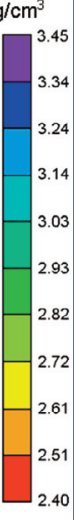

b

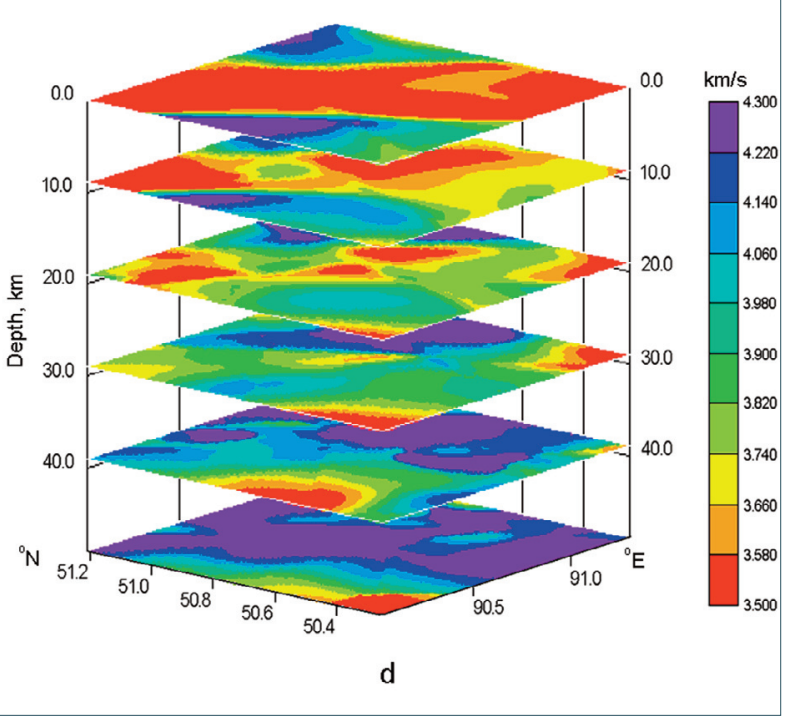

FIGURE 4. Horizontal slices of 3-D models: logarithmic electrical resistivity (a), density (b), velocities of compression and shear seismic waves (c and d, correspondingly) [Spichak et al., 2015].

Taking into account that the background seismicity pattern is often quasi-stationary [Wyss and Toya, 2000; Emanov et al., 2005] one may expect that rock's physical and/or mechanical properties could serve as proxy parameters for constraining ESDs in the crystalline basement of the crust (in this case at the depths below $4 \div 5 \mathrm{~km}$ [Kadurin et al., 2008]).

\subsection{DISCRIMINATING PHYSICAL AND MECHANICAL PROXIES}

In order to find geophysical proxies the physical and mechanical properties of rocks (electrical resistivity, seismic velocities and their ratio, rock density, Poisson ratio, and the bulk, shear, and Young moduli) were compared at the hypocenters of the past earthquakes (see their locations in Figure 3) and in the quiet domains of the crystalline basement (or, more exactly, at the corre- sponding nodes of the spatial grid used previously for calculating these parameters). Their values at the hypocenters were estimated beforehand by artificial neural network interpolation of their values specified at the nodes of the spatial grid to the coordinates of the hypocenters. To this end the ANN was taught by the correspondence between parameters' values and spatial coordinates of the 3D grid nodes where they were assigned followed by their forecasting in the hypocenters' locations (see the algorithm of the artificial neural network forecasting in the Appendix A).

Table 1 summarizes the characteristics of the physical-mechanical properties in the entire area (at the nodes of the spatial grid) and at the hypocenters of the past earthquakes. It is seen that earthquake hypocenters in the study area are characterized, in the mean, by enhanced electrical resistivity and Vp/Vs ratios, and de- 


\begin{tabular}{|c|c|c|c|c|c|c|c|c|c|c|}
\hline & Min & Max & Mean & $\begin{array}{l}\text { Math. } \\
\text { expectation }\end{array}$ & Bars & Min & Max & Mean & $\begin{array}{l}\text { Math. } \\
\text { expectation }\end{array}$ & Bars \\
\hline $\mathrm{Vp}, \mathrm{km} / \mathrm{s}$ & 6.05 & 7.48 & 6.76 & 6.55 & 0.39 & 6.05 & 6.91 & 6.48 & 6.39 & 0.19 \\
\hline $\mathrm{Vs}, \mathrm{km} / \mathrm{s}$ & 3.50 & 4.30 & 3.90 & 3.89 & 0.25 & 3.10 & 4.13 & 3.61 & 3.73 & 0.17 \\
\hline $\mathrm{Vp} / \mathrm{Vs}$ & 1.41 & 2.06 & 1.73 & 1.68 & 0.10 & 1.46 & 1.95 & 1.70 & 1.71 & 0.09 \\
\hline $\mathrm{D}, \mathrm{kg} / \mathrm{m}^{3}$ & 2400 & 3450 & 2920 & 2870 & 170 & 2500 & 3180 & 2840 & 2870 & 110 \\
\hline $\begin{array}{l}\log (\mathrm{R}, \\
\Omega . \mathrm{m})\end{array}$ & 1.0 & 5.0 & 3.00 & 3.49 & 1.19 & 1.0 & 5.0 & 3.00 & 3.71 & 1.00 \\
\hline$P$ & 0 & 0.35 & 0.17 & 0.22 & 0.06 & 0.06 & 0.32 & 0.19 & 0.24 & 0.04 \\
\hline K, GPa & 28.71 & 126.61 & 77.66 & 65.87 & 16.88 & 39.06 & 89.06 & 62.62 & 63.87 & 10.22 \\
\hline G, GPa & 34.52 & 57.35 & 45.93 & 43.60 & 6.15 & 28.81 & 46.23 & 37.52 & 39.75 & 3.03 \\
\hline $\mathrm{Y}, \mathrm{GPa}$ & 43.10 & 71.66 & 57.38 & 53.22 & 7.72 & 38.08 & 57.45 & 47.76 & 49.51 & 3.40 \\
\hline
\end{tabular}

TABLE 1. Characteristics of physical and mechanical parameters in the whole region (in the nodes of the spatial grid) and in the EQ hypocenters (Vp, Vs - velocities of compressional and shear seismic waves, D - density, R - specific electrical resistivity, $\mathrm{K}, \mathrm{G}$ and Y - bulk, shear and Young's moduli, P - Poisson ratio).

creased seismic velocities and elastic moduli. Such anomalies detected during borehole geophysical monitoring are known to be among shallow seismicity precursors related to development of micro-cracks and fractures (see, for instance, [Kuznetsov and Simkin, 1990]). However, situation in depth could be controlled by different processes and corresponding parameters (in particular, by high pressure and temperature).

According to laboratory studies (see, for instance, [Mavko et al., 2009] and references therein) both Vp and Vs velocities are generally increasing with pressure and decreasing with temperature, while $\mathrm{Vp}$ is most sensitive and Vs is less sensitive to the pore fluid content. Depending on interaction of these factors anomalies of seismic velocities as well as of elastic moduli in the locations of hypocenters could be, in general, as positive as negative. For example, Zhao and Kanamori [1995] re- port about prevailing of positive Vp anomaly in 65\% of hypocenters' locations. According to [Krylov and Ten, 1995] Vp anomaly is mainly positive in Kaskelen seismic area while it is mainly negative in Muya seismic area. It is worth mentioning in this connection that hypocenters in the Hengill seismically active geothermal zone (Iceland) are located in the areas characterized by as positive as negative Vp anomalies [Jousset et al., 2010].

Comparative study of the bulk and shear moduli in the hypocenters' locations and "quiet" parts of various seismically active domains indicates that shear modulus is typically reduced (see, for instance, results for $\mathrm{Al}$ tai-Sayan (Figure 5) and for Muya sesmic area [Krylov and Ten, 1995]) while the sign of the relative anomaly of the bulk modulus is not always the same (compare the results for Altai-Sayan (Figure 5), Kaskelen seismic area [Krylov and Ten, 1995] and San Fernando Valley [Zhao 


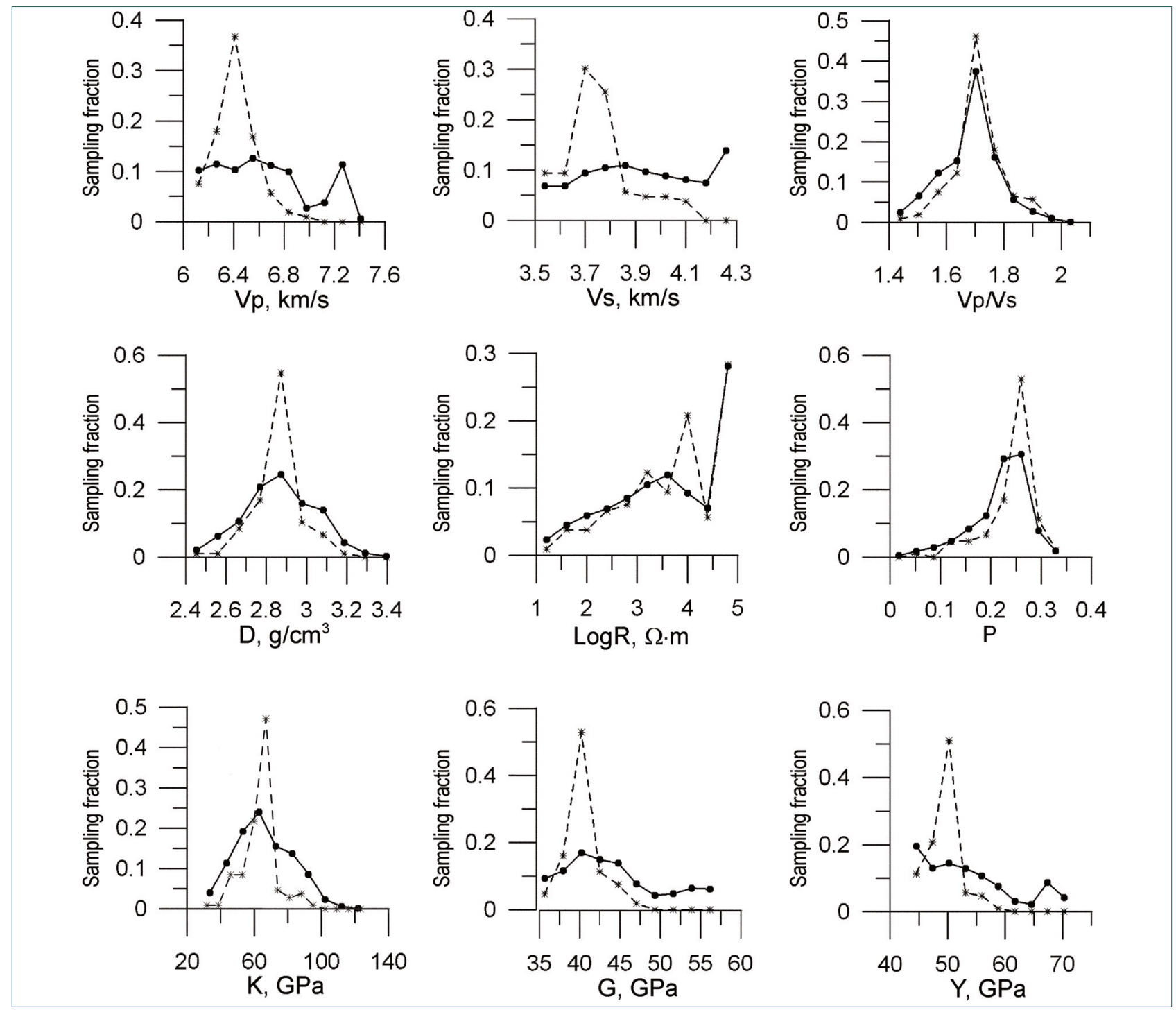

FIGURE 5. Sampling fractions of the physical and mechanical parameters in the whole domain (solid lines) and in the hypocenters of earthquakes (dashed lines): R - electrical resistivity, Vp,Vs - velocities of compression and shear seismic waves, D density, P - Poisson's ratio, G - shear modulus, $\mathrm{K}$ - bulk modulus, Y - Young's modulus.

and Kanamori, 1995]). This is probably caused by the fact that the pore fluid content, which masks the pressure effect, influences Vp but not Vs. Accordingly, the shear modulus, which, in contrary to the bulk modulus, is determined only from Vs velocity, is much less disturbed by this factor.

In this connection it is worth noting that in the opinion of the most of the authors [Chinnery, 1964; Martel and Pollard, 1989; Du and Aydin, 1995; Bormann et al., 2009; Stefanov and Bakeev, 2014; among others] fracturing of the deep rocks in the source zones of the crustal earthquakes occurs mainly in the form of the strike-slip faulting, to which the shear modulus is most sensitive. However, generally speaking, the forms of fracturing could be different (see, for instance, [Bormann et al., 2009]), so, using of different elastic moduli for constraining ESDs seems to be more reliable.

In order to compare statistical distributions of all considered parameters their sampling fractions were determined at the nodes of the regular spatial grid covering the study volume and at the earthquake hypocenters. They were calculated as numbers of samples normalized by the total numbers of grid nodes and hypocenters, accordingly. Figure 5 shows the graphs of sampling fractions for all parameters determined in the hypocenters and the rest ("quiet") domain. Comparison of the graphs indicates that the sampling fraction maxima of the elastic moduli ( $\mathrm{G}$, and $\mathrm{Y}$ ) and, to a lesser degree, seismic Vp and Vs velocities at the hypocenters's locations noticeably differ from the rest of the medium and that they correspond to the significantly different values of the appropriate parameters. At the same time, 
the maxima of the sampling fraction for other parameters differ from the values in the remaining medium but correspond to almost identical values of the parameters. The revealed distinctions form a basement for selecting above mentioned parameters for constraining ESDs.

\subsection{CONSTRAINING EARTHQUAKE SOURCE DO- MAINS}

According to [Spichak, 2016] EQ source domains in the study area could be constrained using geophysical proxies. An appropriate algorithm of "unsupervised learning” similar to K-means clastering technique (see, for instance, [Kanungo et al., 2002]) is described below.

Let us bin all physical-mechanical parameters $F_{n}$ $(n=1, \ldots, 9)$ considered above into the intervals $\left[A_{i}-\sigma_{i}\right.$, $\left.A_{i}+\sigma_{i}\right]$, where $A_{i}$ and $\sigma_{i}$ are expected values and variances of the i-th parameter, respectively, estimated from the assemblage of their values at the hypocenters of the past earthquakes. Determine individual characteristic functions for each parameter $F_{n}$ as follows:

$$
\chi_{n}\left(\mathrm{x}_{i}, \mathrm{y}_{i}, z_{i}\right)=\left\{\begin{array}{l}
1, \text { if } \mathrm{F}_{n}\left(\mathrm{x}_{i}, \mathrm{y}_{i}, z_{i}\right) \in\left[A_{n}-\sigma_{n}, A_{n}+\sigma_{n}\right] \\
0, \text { if } \mathrm{F}_{n}\left(\mathrm{x}_{i}, \mathrm{y}_{i}, z_{i}\right) \notin\left[A_{n}-\sigma_{n}, A_{n}+\sigma_{n}\right](5)
\end{array}\right.
$$

where $F_{n}\left(\mathrm{x}_{i}, \mathrm{y}_{j}, \mathrm{z}_{l}\right)$ is a value of $\mathrm{n}$-th parameter in the grid node $(i, j, l)$. Then functions, consisting from all possible multiplications

$\chi=\prod_{n=n 1}^{n=n 2} \chi_{n}\left(x_{i}, y_{j}, z_{k}\right), \quad(i=l, \ldots, I ; j=l, \ldots, J ; l=l, \ldots, L ; n l, n 2: 1, \ldots, N)$

form a multitude of geophysical proxies of potential EQ source domains. In other words, $\chi$ constrains crustal domains having a common property: each elementary volume pixel is characterized by geophysical proxies typical for past EQ hypocenters and therefore could be considered as a candidate for future earthquake source.

As it was found in the previous section, seismic velocities (Vp, Vs) and elastic moduli (G, Y) are the most appropriate geophysical proxies for constraining ESDs. Accordingly, multiplication of their characteristic functions $\chi=\chi_{V p} \chi_{V s} \chi_{G} \chi_{Y}$, determined according to (5) could be used for spatial delineating of the potential EQ source domains.

Figure 6a demonstrates the locations of EQ source domains revealed according to the algorithm described above. One can see that they are distinguished along the depth rather than laterally (as would be the case if the locations of source zones were controlled by the fault tectonics). The deepest echelon located at a depth of about $35 \div 40 \mathrm{~km}$ in the southeastern part of the region is

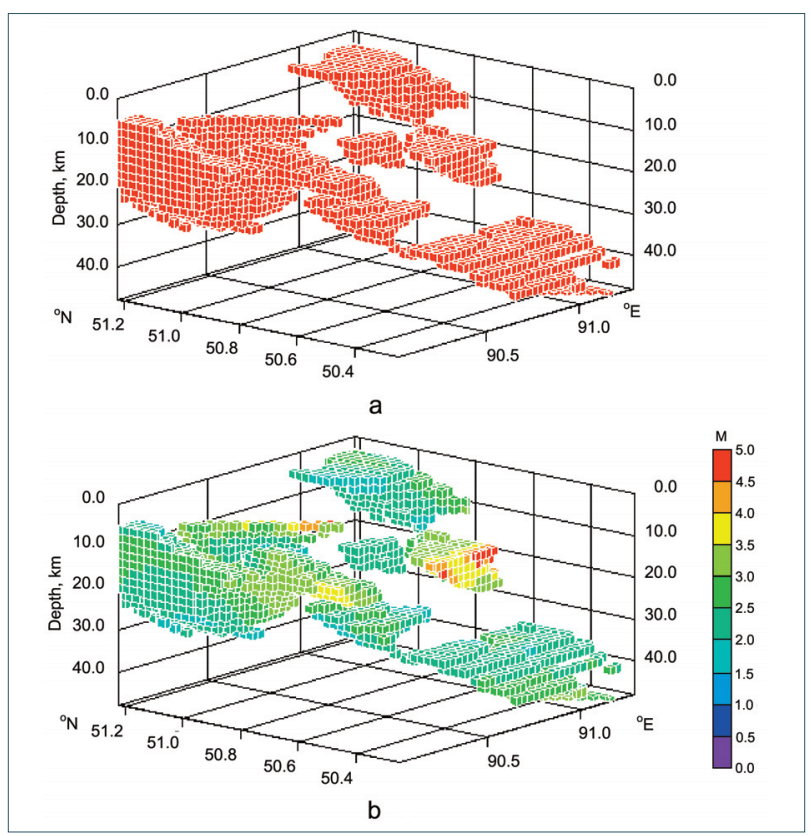

FIGURE 6. a: earthquake source domains constrained using geophysical proxies selected from the available data; $b$ : potential EQ magnitudes in the earthquake source domains estimated from shear modulus and past seismicity.

likely to coincide with the Shapshal "source zone", which was previously supposed based on the statistical analysis of the surface seismicity data (see Section 2.1). Another echelon located at a depth of $20 \div 30 \mathrm{~km}$ in the northwestern segment of the study area looks like a part of the Teelin "source zone", which was also hypothesized previously (see Section 2.1).

Besides, there are 5 source zones located at depths of about $10-30 \mathrm{~km}$ in the northern and central parts of the region. Finally, the source zone is observed in the depth range from the boundary of the crystalline basement to about $10 \mathrm{~km}$ in the northeastern part of the area. In contrast to the former two domains whose horizontal positions were predicted from the data on surface seismicity and interpreted in terms of the fault tectonics, the locations of other source domains have been determined for the first time. Thus, with the new approach we have not only constrained the spatial location of the ESDs, but also revealed their fine structure.

\section{ESTIMATING EXPECTED MAGNITUDES OF POTENTIAL EARTHQUAKES}

Supposing that future earthquakes are attributed to existing faults it is, in principle, possible to estimate their expected magnitudes using possible correlation between the rapture geometrical parameters and mag- 
nitudes of past events [Bonilla et al., 1984; Wells and Coppersmith, 1994; among others]. However, using this approach it would be difficult to predict the magnitudes in the areas, where the faults are rare or are not outcropping.

Some earthquake forecasting models assume that the magnitude of any earthquake is independent from the past [Kagan and Knopoff, 1977; Reasenberg and Jones, 1989; Zhuang et al., 2011]. On the other hand, "the magnitude distribution does not seem to be independent of the history of the occurrences" [Ogata, 1988]. This inference is implicitly used by some authors who predict the intensity of the next earthquake to be held in the same area based on the neural network analysis of past seismicity [Panakkat and Adeli, 2007; Adeli and Panakkat, 2009; Alarifi et al., 2012; Last et al. 2016].

In this connection it is important mentioning that all cited above authors formally predict future intensities of the earthquakes at the surface based on past seismicity records in the same area. Meanwhile, the intensities in the epicenters depend not only on the spatial distribution of the EQ magnitudes in the EQ hypocenters but also on many other factors (like subsurface rock properties) often varying with time in unpredictable way. So, instead of formal predicting the EQ intensities at the surface it seems more justified to estimate their potential magnitudes in the source domains.

According to [Zhalkovskii, 1989; Zhalkovskii et al., 1995] the material composition of the rocks in the source zones, their physical characteristics, the type of deformations and rate of strain of the rocks only affect the frequency of nucleation of the earthquakes but not the character of their distribution by magnitudes. Based on this statement these authors conclude: "such insensitivity of the law of earthquake recurrence to the conditions of their preparation means that each nucleated earthquake can reach any arbitrary magnitude during its evolution". Meanwhile, this "insensitivity" only refers to the occurrence conditions of an earthquake but not to the physical and mechanical properties of rocks which control the spatial distribution of the earthquake hypocenters (see Section 4.1). Basing on this inference it could be possible to develop an approach for predicting magnitudes of the potential earthquakes in the ESDs from the rocks' properties and data on past EQ magnitudes in the hypocenters.

\subsection{ARTIFICIAL NEURAL NETWORK APPROACH}

In order to forecast expected magnitudes of future earthquakes in the EQ source domains constrained above (see Section 4.2) the neural network based technique was used (see Appendix A for details). In the context of this study it is important to note that according to [Spichak and Goidina, 2016] the results of the neural network forecasting depend on the relation of one parameter to another rather than on their correlation on the considered set of data. The neural network analysis of the sensitivity of the physical and mechanical properties of rocks to the magnitude of the earthquakes has resulted in the following hierarchy of the parameters (in the descending order of sensitivity to magnitude values): G, Vs, Y, Vp, Vp/Vs, LogR, P, K and D. (It is worth mentioning in this connection that 4 parameters selected in the Section 4.2 for ESD constraining are at the top of this list.)

In accordance with this hierarchy the G modulus characterizing the shear strength of rocks was selected for the neural network estimating of the earthquake magnitudes in the locations of potential earthquakes determined above. It is worth mentioning in this connection that this selection is supported by inferences of [Kanamori, 1977] and [Krylov and Duchkov, 1996] who state that the shear modulus is the main rock property affecting the magnitude of the earthquake.

Neural network forecasting of possible EQ magnitudes in the source domains was fulfilled in three steps: training and testing of the network followed by forecasting of the EQ magnitudes.

\subsection{TRAINING AND TESTING OF THE NEURAL NET- WORK}

At the step of training, ANNs were taught by correspondence of the $G$ modulus values at the hypocenters of past earthquakes and their coordinates to the magnitudes $M$ of these events taken from the created data base (see Section 2.2 above). At the ANN validation, the magnitudes were forecasted at the hypocenters which have not been used in training. For this purpose, the entire pool of the initial data was five times randomly subdivided in the proportion $4: 1$. Each time, the neural networks were trained on the larger part of the data samples (80\%) and tested on the smaller part of the data (20\%). The relative testing errors in five cases were $13.3 \%, 23.0 \%, 34.5 \%, 22.7 \%$, and 35.5\% with an average error of $25.8 \%$. It is worth noting in this respect that not so high average accuracy of the predic- 
tion is directly related to the relatively small number of the high-quality data for the hypocenters of the past earthquakes which were used for training of the ANN. The experience shows (see, for instance [Spichak, 2011]) that the relative errors of the forecasts sharply decrease (up to a few first percents) with the increase in the volume of data used for ANN training. So, one might expect that using more data on past seismicity (including accurate estimates of all three coordinates of hypocenters) could significantly improve the results.

\subsection{FORECASTING EXPECTED MAGNITUDES OF THE EARTHQUAKES}

The artificial neural network, which was trained and tested on all the data for earthquake hypocenters, was used then for estimating their expected magnitudes in the EQ source zones constrained above (see Section 4.2) from the values of the shear modulus. Figure $6 b$ shows the model of the probable magnitudes of the potential earthquakes in the revealed ESDs built using the ANN trained as described above. Note that each volume pixel has the same dimensions as node spacing in the models above: $2 \mathrm{~km}$ in the horizontal directions and $1 \mathrm{~km}$ in depth.

The analysis of the magnitudes in this model shows that they are generally low $(1 \div 2)$, and the highest magnitudes (up to 5) correspond to the depths of around $15 \mathrm{~km}$ at the latitude $50.6^{\circ} \mathrm{N}$ recorded in this location earlier (Figure 2b).

\section{CONCLUSIONS}

A two-stage algorithm is developed for constraining EQ source domains and estimating expected (not maximal!) EQ magnitudes. At the first stage constraining of the ESDs from most appropriate geophysical proxies (elastic moduli and seismic velocities) is carried out. Its application to the seismically active area of the AltaiSayan region enabled to delineate such domains at different depths. Two of them were previously guessed from the surface seismicity data and interpreted in terms of the fault tectonics, whereas others have been constrained for the first time. This supports the inference that neither the statistical information on past seismicity alone nor speculations on fault tectonics are sufficient to constrain the ESDs in the Earth's crust.

At the second stage estimating of the expected EQ magnitudes is fulfilled in the ESDs constrained at the first stage. To this end artificial neural network was taught by the values of the shear modulus (most sensitive to EQ magnitudes) determined in the hypocenters of past earthquakes and their magnitudes. ANN magnitude forecasting in the Altai-Sayan area indicates that maximal expected magnitude in the mean coincides with that observed in the study area since 1962.

Spatial distribution of the potential EQ magnitudes in the source domains is a good basement for seismic zoning in the regional scale (say, 1:200000). It could be carried out by integrating over the source domains taking into account mechanical properties of sedimentary rocks and strain accumulation estimated from GPS data. In turn, the latter results could be used for scientifically grounded planning of the spatial distribution of seismic stations aimed at monitoring and forecasting of seismic events taking into account local conditions.

The proposed algorithm for ESP constraining and potential EQ magnitude estimating is actually a regular tool to be used for achieving appropriate goals depending on the volume and quality of the seismicity and geophysical data available at that moment. Its applicability is not based on explicit or implicit assumptions on the character of the seismicity and does not depend on the time factor. On the other hand, development of the scientifically justified methodology for forecasting locations and magnitudes of possible seismic events based on the proposed algorithm requires further studies in seismically active areas located in different geological environments. In doing so, the most important would be to estimate the impacts of the volume and accuracy of both geophysical and past seismicity data used for both ESD constraining and earthquake magnitude estimating on the resulting uncertainties.

Finally, the results of research indirectly support the hypothesis of the common physical and mechanical conditions controlling the occurrence of the earthquakes and evolution of the faults. The rheological weakness of rocks which experience shearing deformations under the action of external stresses (regardless of their origin) and are then cut by the faults of different rank is likely to be responsible for these common conditions. In other words, the provided research gives an impetus to change the paradigm of the $\mathrm{EQ}$ forecast based on fault tectonics to constraining potential ESDs in the crystalline crust from geophysical sounding data. 
Acknowledgements. The author is grateful to Dr. Natalia A. Sergeeva, Director of the Moscow Department of the World Data Center, for providing the data on the seismicity of the Altai-Sayan region. The author deeply acknowledges the anonymous reviewer and Ass. Editor Dr. Fabio Cammarano for valuable critical comments, which helped to improve the manuscript.

\section{REFERENCES}

Adeli, H. and A. Panakkat (2009). A probabilistic neural network for earthquake magnitude prediction, Neural Networks, 22, 1018-1024.

Alarifi, A.S.N, N.S.N. Alarifi, S. Al-Humidan (2012). Earthquakes magnitude prediction using artificial neural network in northern Red Sea area, Journal of King Saud University - Science, 24, 301-313.

Artikov, T.U., R.S. Ibragimov, T.L. Ibragimova, and M.A. Mirzaev (2016). Study of modern seismic zoning maps' accuracy (case for Eastern Uzbekistan), Geodesy and Geodynamics , 17 (6) , 416 - 424.

Blagovidova, T.Ya., N.D. Zhalkovsii, V.I. Muchnaya, A.G. Filina and I.D. Tsirulchik (1986). Seismicity of the Altai-Sayan region from instrumental data, Russian Geology and Geophysics, 1, 140-147.

Bonilla, M.G., R.K. Mark, and J.J. Lienkaemper (1984). Statistical relations among earthquake magnitude, surface rupture length and surface fault displacement, USGS Open-File Report 84-256. - 46pp.

Bormann, P., M. Baumbach, G. Bock, H. Grosser, G. Choy and J. Boatwright (2009). Seismic Sources and Source Parameters. - In: Bormann, P. (Ed.), New Manual of Seismological Observatory Practice (NMSOP), Potsdam : Deutsches GeoForschungsZentrum GFZ, 1-94.

Caputo, M., V. Keilis-Borok, E. Oficerova, E. Ranzman, I. Rotwain and A. Solovjeff (1980). Pattern recognition of earthquake prone areas in Italy, Phys. Earth Planet Int., 21, 305-320.

Chatzipetros, A., S. Pavlides and D. Mountrakis (1998). Understanding the 13 May 1995 Western Macedonia Earthquake: A Paleoseismological Approach, J. Geodynamics, 26(2-4), 327-339.

Chinnery, M. A. (1964) The Strength of the Earth's Crust under Horizontal Shear Stress, J. Geophys. Res., 59(10), 2085-2089.

Du, Y. and A. Aydin (1995). Shear fracture patterns and connectivity at geometric complexities along strike-slip faults, J. Geophys. Res., Solid Earth,
100(B9), 18093-18102

Earthquakes in Northern Eurasia (1992-2005) (2005), in Catalog of Geophysical Survey of RAS, E. Starovoit (Editor), Obninsk (in Russian).

Earthquakes in the USSR (1962-1991) (1991), M. Sadovsky M. (Editor), Nauka Publ., Moscow (in Russian).

Emanov, A.F., A.A. Emanov, A.G. Filina and E.B. Leskova (2005). Spatial-temporal pecularities of the AltaiSayan seismisity, Physical Mesomechanics, 8(2), 49-64 (in Russian).

Eppelbaum, L.V. and Y.I. Katz (2016). Tectono-Geophysical Zonation of the Near and Middle East and Eastern Africa, Intern. J. of Geology, 10, 1-10.

Frankel, A., C. Mueller, T. Barnhard, D. Perkins, E. Leyendecker, N. Dickman, S. Hanson and M. Hopper (1996). National Seismic Hazard Maps Documentation, U.S. Geol. Surv. Open-File Report 96-532. U.S. Government Printing Office, Washington, D.C.

Gao, Meng-tan (2003). New national seismic zoning map of China, Acta Seismologica Sinica, 16 (5), 639-645.

Gelfand, I.M., Sh.A. Guberman, M. Izvekova, V.I. KeilisBorok and E.Ya. Rantsman (1972). Criteria of high seismicity determined by pattern recognition, Tectonophysics, 13 (1-4), 415-422.

Gorshkov A., V. Kossobokov and A. Soloviev (2003). Recognition of earthquake-prone areas. In: Nonlinear Dynamics of the Lithosphere and Earthquake Prediction V. Keilis-Borok and A. Soloviev (Editors), Springer, Heidelberg, 239-310.

Gorshkov, A.I., G.F. Panza, A.A. Soloviev, A. Aoudia and A. Peresan (2009). Delineation of the geometry of nodes in the Alps-Dinarides hinge zone and recognition of seismogenic nodes, Terra Nova, 21, 257264.

Gvishiani, A.D., B. A. Dzeboev, N. A. Sergeeva, I. O. Belov, and A. I. Rybkina (2018). Significant Earthquake-Prone Areas in the Altai-Sayan Region. Izvestiya, Physics of the Solid Earth, 54(3), 406414.

Harrison, R.W. and A. Schultz (1994). A strike-slip faulting at the thebes gap, Missoury and Illinois: Implication for New Madrid Tectonism, Tectonics 13(2), 246-257.

Haykin, S (1998). Neural networks: a comprehensive foundation. 2nd edn., Prentice-Hall, New York.

Jonson, A.M. and R.W. Fleming (1993). Formation of left-lateral fractures within the Summit ridge shear 
zone, 1989 Loma Prieta, California, Earthquake. J. Geophys. Res., 98(B12), 21,823-21,837.

Jousset, P., C. Haberland, K. Bauer, K. Árnason (2010). Detailed structure of the Hengill geothermal volcanic complex, Iceland, inferred from 3-D tomography of high-dynamic broadband seismological data, Expanded Abstr. World Geothermal Congress, Bali, Indonesia.

Kadurin, I.N., V.V. Belyavskii and A.V. Egorkin (2008). Geophysical study of the deep structure of AltaiSayan folded belt: seismic and resistivity prospecting along the 3300-km long profile. The design and implementation of the field geophysical observations at the Tyva testing site. Tech. Rep. Geolfond. -244 pp. (in Russian).

Kagan, Y.Y. and L. Knopoff (1977). Earthquake risk prediction as a stochastic process, Phys. Earth planet. Inter., 14, 97-108.

Kanamori, H. (1977). Energy release in great earthquakes, Journal of Geophysical Research, 82, 2981-2987.

Kanungo, T., D.M. Mount, N. S. Netanyahu, C.D. Piatko, R. Silverman, and A.Y. Wu. (2002). An Efficient kMeans Clustering Algorithm: Analysis and Implementation. IEEE Trans. Pattern analysis and machine intelligence, 24 (7), 881-892.

Khair, K., G.F. Karakaisis and E.E. Papadimitriou (2000). Seismic zonation of the Dead Sea transform fault area, Annali di Geofisica, 43(1), 61-79.

Kossobokov, V.G., V.I. Keilis-Borok, D.L. Turkotte and B.D. Malamud (2000). Implications of a statistical physics approach for earthquake hazard assessment and estimating, Pure Appl. Geophys., 157, 2323-2349.

Krylov, S.V. and A.D. Duchkov (1996). Deep strainstrength regionalization of the Earth's crust, Russian Geology and Geophysics, 37(9), 56-65.

Krylov, S.V. and E.N. Ten (1995). Strength and elastic properties of source zones of violent earthquakes within the Baikal and northern Tien Shan areas, Russian Geology and Geophysics, 36(2), 137-150.

Kuznetsov, O.L. and E.M. Simkin (1990). Transformation and interaction of geophysical fields in the lithosphere. - Moscow, Nedra Publ. (in Russian).

Last, M., N. Rabinowitz, and G. Leonard (2016). Predicting the Maximum Earthquake Magnitude from Seismic Data in Israel and its Neighboring Countries, PLOS ONE, DOI:10.1371/journal.pone.0146101.
Leonard, M., D. Burbidge. and M. Edwards (2013). Atlas of Seismic Hazard Maps of Australia. Geoscience Australia Publ.

Lomnitz, C.A. (1974). Global tectonics and earthquake risk. Elsevier, Amsterdam.

Maps of regional seismic zoning of the territory of Russian Federation (OCP-97) in the scale 1:8000000 (1999). Institute of the Physics if the Earth RAS Publ., Moscow (in Russian).

Martel, S.J., D.D. Pollard (1989). Mechanics of Slip and Fracture Along Small Faults and Simple Strike-Slip Fault Zones in Granitic Rock, J. Geophys. Res., 94(B7), 9417-9428.

Mavko, G., T. Mukerji and J. Dvorkin (2009). The rock physics handbook, 2nd edition. Cambridge University Press.

Mohapatra, A.K. and W.K. Mohanty (2010). An Overview of Seismic Zonation Studies in India, in Proc. Indian Geotechnical Conference, GEOtrendz, December 16-18.

Mulargia, F., P.B. Stark and R.J. Geller (2017). Why is Probabilistic Seismic Hazard Analysis (PSHA) still used? Physics of the Earth and Planetary Interiors, 264, 63-75, doi: 10.1016/j.pepi.2016.12.002.

Mulargia, F., G. Visconti and R.J. Geller (2018). Scientific principles and public policy, Earth-Science Reviews, 176, 214-221.

Murthy, Y. (2002). On the correlation of seismicity with geophysical lineaments over the Indian subcontinent, Current Science, 83, 760-766.

New Madrid seismic zone: overview of earthquake hazard and magnitude assessment based on fragility of historic structures (2003). NAHB Research Center Upper Marlboro, MD, USA.

Ogata, Y. (1988). Statistical Models for Earthquake Occurrences and Residual Analysis for Point Processes, J. American Statistical Association, 83(401), 9-27.

Panakkat, A., H. Adeli (2007). Neural network models for earthquake magnitude prediction using multiple seismicity indicators, International Journal of Neural Systems, 17, 13-33.

Petrini, V. and M.P. Boni (2004). Seismic zonation criteria in Italy: analysis on methodologies and parameters. - In: Proc. 13th World Conference on Earthquake Engineering, Vancouver, B.C., Canada, August 1-6, Paper No. 3322.

Putra, R.R., J. Kiyono, Y. Ono and H.R. Parajuli (2012). Seismic hazard analysis for Indonesia, J. Nat. Dis- 
aster Science, 33(2), 59-70.

Reasenberg, P.A. and L.M. Jones (1989). Earthquake hazard after a mainshock in California, Science, 243 (4895), 1173-1776.

Scitovski, S. (2018). A density-based clustering algorithm for earthquake zoning, Computers and Geosciences, 110, 90-95.

Solomos, G., A. Pinto and S. Dimova (2008). A review of the seismic hazard zonation in national building codes in the context of Eurocode 8, JRC Publ., Italy.

Spichak, V.V. (2011). Application of ANN based techniques in EM induction studies. - In: The Earth's Magnetic Interior E. Petrovský, E. Herrero-Bervera, T. Harinarayana and D. Ivers (Editors), IAGA Special Sopron Book Series, 1, Springer, 19-30.

Spichak, V.V. (2016). Constraining Potential Earthquake Sources from the Geophysical Data, Izvestiya, Physics of the Solid Earth, 52(1), 45-56.

Spichak, V.V., I.A. Bezruk and A.G. Goidina (2015). 3-D claster models of the Altai-Sayan area built from the geophysical data collected along regional transects, Prospecting and Managing the Earth's Resources, 4, 41-45 (in Russian).

Spichak, V.V. and A.G. Goidina (2016). Neural network estimate of seismic velocities and resistivity of rocks from electromagnetic and seismic data, respectively. Izvestiya, Physics of the Solid Earth, 52 (3), 371-381.

Stefanov, Yu.P. and R.A. Bakeev (2014). Deformation and fracture structures in strike-slip faulting, Engineering Fracture Mechanics, 129, 102-111.

Stein, S., R.J. Geller and M. Liu (2012). Why earthquake hazard maps often fail and what to do about it? Tectonophysics, 562-563, 1-25.

Stein, S. and M. Wysession (2005). An Introduction to Seismology, Earthquakes and Earth Structure. Blackwell Publ.

The San Andreas Fault System, California (1990). USGS Professional Paper 1515, Washington.

Udías, A., and E. Buforn (2012). Source Mechanisms of Earthquakes. Theory and practice. Cambridge University

Press. doi.org/10.1017/CB09781139628792.009.

Vamvakaris, D.A., C.B. Papazachos, Ch.A. Papaioannou, E.M. Scordilis and G.F. Karakaisis (2016). A detailed seismic zonation model for shallow earthquakes in the broader Aegean area, Nat. Hazards Earth Syst. Sci., 16, 55-84.
Wald, D., T. Heaton and L. Wald (1994). Rupture analysis of the Northridge earthquake from modeling strong motion recordings, Earthquakes and Volcanoes, 25(1), 42-47.

Wells, D.L. and K.J. Coppersmith (1994). New empirical relationships among magnitude, rupture length, rupture width, rupture area and surface displacement, Bull. Seism. Soc. Am., 84(4), 974-1002.

Wenk, T. (2014). Seismic zoning map of Switzerland. In: Proc. Workshop on Results of European project SHARE: Seismic hazard harmonization in Europe, DGEB e.V., 43-52.

Wyss, M. and Y. Toya (2000). Is background seismicity produced at a stationary Poissonian rate? Bull. Seism. Soc. Am., 90 (5), 1174-1187.

Zaalishvili, V.B. and E.A. Rogojin (2011). Assessment of Seismic Hazard of Territory on Basis of Modern Methods of Detailed Zoning and Seismic Microzonation, The Open Construction and Building Technology Journal, 5, 30-40.

Zhalkovskii, N.D. (1989). On the magnitudes and recurrence of the strongest earthquakes, Russian Geology and Geophysics, 9, 99-105.

Zhalkovskii, N.D., O.A. Kuchai and V.I. Muchnaya (1995). Seismicity and some characteristics of the stressed state of the Earth's crust in the Altai-Sayan region, Russian Geology and Geophysics, 36 (10), 20-30.

Zhao, D. and H. Kanamori (1995). The 1994 Northridge earthquake: 3-D crustal structure in the rupture zone and its relation to the aftershock locations and mechanisms, Geophys. Res. Lett., 22(7), 763766.

Zhuang, J., M.J. Werner, S. Hainzl, D. Harte and S. Zhou (2011). Basic models of seismicity: spatiotemporal models, Community Online Resource for Statistical Seismicity Analysis, doi:10.5078/corssa-07487583.

*CORRESPONDING AUTHOR: Viacheslav SPICHAK, Affiliation: Institute of the Physics of the Earth, Russian Academy of Sciences,

Moscow Russia email: v.spichak@mail.ru 


\section{Appendix A. Artificial neural network with a teacher ["back-propagation technique"]}

In this section, we only consider the principles of operation of the artificial neural network (ANN) with a teacher, or the error back-propagation (BP) technique (see [Haykin, 1998] and references therein), which was used for predicting the earthquake magnitudes from the shear modulus.

In our case the neural network was composed of three layers - input, hidden and output (Figure A1). The input neurons are the values of the shear modulus and appropriate spatial coordinates, while the output neurons are the magnitudes of the earthquakes in the predetermined locations. The neurons of each two neighboring layers are linked by connection weights $w_{\mathrm{ik}}$, where $i, j$ are the indices of the neurons of the previous and the next layers. The architecture of this neural network establishes these connections by the "each with each" principle for each pair of the neighboring layers.

The input signal propagates in this network in the following way. Input signal $x_{i}$, equal to the value of the corresponding element of the input vector, is supplied to each $i$-th neuron of the input layer. Each $k$-th neuron of the hidden layer receives a total input signal $y_{k}^{i n p}$ from all the neurons of the previous layer:

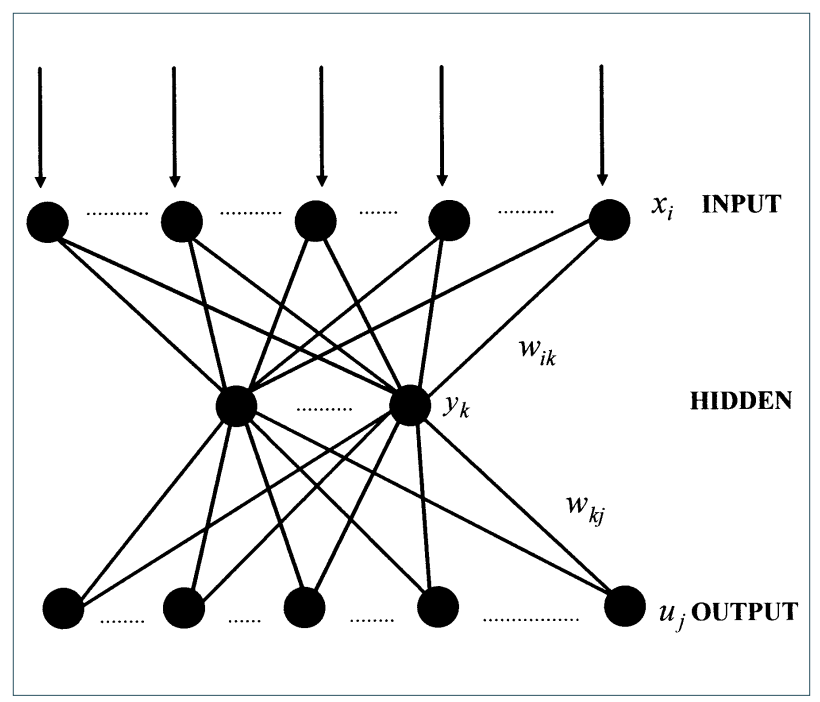

FIGURE A1. Three-layer artificial neural network.

$$
y_{k}^{i n p}=\sum_{i} w_{i k} x_{i}
$$

where $w_{i k}$ are the connect coefficients (weights) between the input and hidden layers and the summation is carried out over all the neurons of the previous layer. The neurons of the hidden layer and the neurons of the output layer transform this input signal $y_{k}^{\text {inp }}$ into the output signal $y_{k}^{\text {out }}$ through the so called "activation function" of a neuron $G_{k}^{h}$ :

$$
y_{k}^{\text {out }}=G_{k}^{h}\left(y_{k}^{\text {inp }}\right)
$$

Then the signals propagate from a hidden layer to the output one and for each $j$-th neuron of the output layer we obtain:

$$
u_{j}=G_{j}^{u}\left(\sum_{k} w_{k j} y_{k}^{o u t}\right)
$$

where $u_{j}$ are the output signals at the output layer, $w_{k j}$ are the connection weights between the hidden and output layers and $G_{j}^{u}$ are activation functions for neurons at output layer.

At the training stage the actual output signals $u_{j}$ are compared with known "correct answers" $u_{j}^{t}$, which correspond to given input signals, and a standard error

$$
\operatorname{Er}_{p}=\sum_{j}\left(u_{p, j}-u_{p, j}^{t}\right)^{2}
$$

is calculated for each $p$-th learning sample; here the summation is carried out over all neurons of the output layer. The term "learning sample" means a correspondence " $\mathrm{G}$ modulus values at the hypocenters of past earthquakes and their coordinates - magnitudes M of these events".

Such input - output pairs are defined by the "teacher" and compose the ANN training sequence. The total error to be minimized is

$$
E r=\left(\frac{1}{P} \sum_{p} E r_{p}\right)^{1 / 2}
$$

where the summation is performed over all $P$ learning samples.

The connection weights $w_{\mathrm{ik}}$ and $w_{\mathrm{kj}}$ are the parameters that determine the signal propagation through the network and, therefore, the final error. BP is actually a gradient descent technique minimizing the error $E r$ by means of adjusting the connection weights:

$$
\Delta w_{i j}^{(n)}=-\alpha \frac{\partial E r}{\partial w_{i j}}+\Delta w_{i j}^{(n-1)}
$$


where is the training rate and $\beta(0 \leq \beta \leq 1)$ is the inertial coefficient called "learning momentum".

Learning starts from small random values of the weights. The input signal comes via network to the output. The output signal of the output layer is compared then with the desired value and the misfit is calculated. If it exceeds predetermined small number, the signal propagates back through the network to the input, and so on. This procedure is fulfilled for the whole learning pool and ends upon reaching a user-specified threshold value Eps $(E r<E p s)$ named further "a teaching precision”. In particular, for solving the task of neural network estimating the distribution of probable magnitudes, the neural network was trained up to reaching the threshold accuracy of 1\%, which, according to the experience in using the artificial neural networks in the problems of geoelectrics [Spichak, 2011] was sufficient for achieving the 5-10\% accuracy of recognition of the sought parameters.

The testing (recognition) procedure makes use of the ability of the neural network to interpolate and extrapolate the data. In contrast to the training procedure which requires many steps for a signal to propagate forward and back through the network, the recognition procedure only requires a single passage of a signal to be recognized from the input to the output of the network. This procedure is implemented with the connection weights containing the "inference rules", which were established at the training step. The final result, which is formed at the output, can be treated as the potential earthquake magnitudes forecasted at the given nodes of the spatial grid from the values of the shear modulus determined earlier. 